\title{
Industrial Liquid Pool Propene Polymerization With METALlOCENE/MAO/Silica CATALYST SySTEMS
}

\author{
B. Tesche, S. Knoke, F. Korber, G. Fink \\ Max-Planck-Institut für Kohlenforschung, Mülheim an der Ruhr, Germany
}

Introduction

The discovery of metallocene/methylaluminoxane (MAO) catalysts for olefin, diene and styrene polymerization has opened a new chapter in the book of polymer science. Beside the classical Ziegler and Phillips catalyst systems this new generation of polymerization catalyst allows control of the polymer tacticity, molar mass and molar mass distribution with greater efficiency. New kinds of copolymers and elastomers can be synthesized. Metallocene/MAO catalysts have been introduced already by most major manufacturers to large scale polyolefin production in gas phase and liquid pool (liquid monomer) based processes. Supported catalyst systems are necessary so that existing production plants can be used with the so-called "drop in technology". Commonly, spherical porous silica is used to support the metallocene catalyst and MAO as cocatalyst. The silica support breaks down during polymerization from an original sphere size of about $50 \mu \mathrm{m}$ to fragments of about 10 $\mathrm{nm}$ grain size, driven by hydraulic forces of the produced polymer. These tiny silica fragments, in small concentrations, do not influence the product properties and it is not necessary to remove them. ${ }^{1}$ Nevertheless metallocene/MAO based polymer production is already running on a large scale, the supporting procedure is still under strong investigation.

\section{Results}

We have studied the elemental distribution of the metallocene catalyst and MAO cocatalyst on the silica support. Several industrially used catalyst systems were embedded in epoxy resin and sectioned. The corresponding block face was investigated by means of SEM/EDX. A common problem is the inhomogeneous distribution of the MAO cocatalyst on the silica support. Fig. 1 shows a typical example of such a catalyst system. In some particles Al is homogeneously distributed throughout the particle. Some others show a strong enrichment of Al on the outer surface of the silica grains coupled with lower Al content in the particle interior. Others show a low Al content throughout the whole particle.

We have investigated in great detail ${ }^{2}$ the polymerization behavior of this system under industrial conditions in liquid propene with calorimetric detection of the generated reaction heat. To study the fragmentation process we have stopped polymerization after low propene turnovers at several time intervals between 0,5 and 3 minutes. Fig. 2 shows a plot of polymer yield versus polymerization time. SEM micrographes of the corresponding polymer samples reveal that the number of fragmented particles increases with time. After 0,5 minutes only small shells of polymer have developed and support fragmentation has just started. After 1,5 minutes some particles are still almost unfragmented and others seem to consist of polymer only, which means fragmentation is in an advanced state already. After 3 min most particles have started to undergo fragmentation. Figure 3 shows SEM/EDX measurements of the $\mathrm{Si} / \mathrm{Al}$ ratios corresponding to certain particles in a polymerization stopped after 1,5 min. It is obvious that reacted particles show a significantly higher $\mathrm{Al} / \mathrm{Si}$ ratio than the unreacted ones. That means we can correlate a delayed fragmentation, resulting in a low initial polymerization activity to particles with low or uneven Al-distribution. Particles with a high Al content and an even Al-distribution show much faster fragmentation, resulting in higher 
initial polymerization activity. Strongly supportive results were obtained with in situ video microscopic observation of propene polymerization with metallocene/MAO/silica catalyst systems in the gas phase. ${ }^{3}$
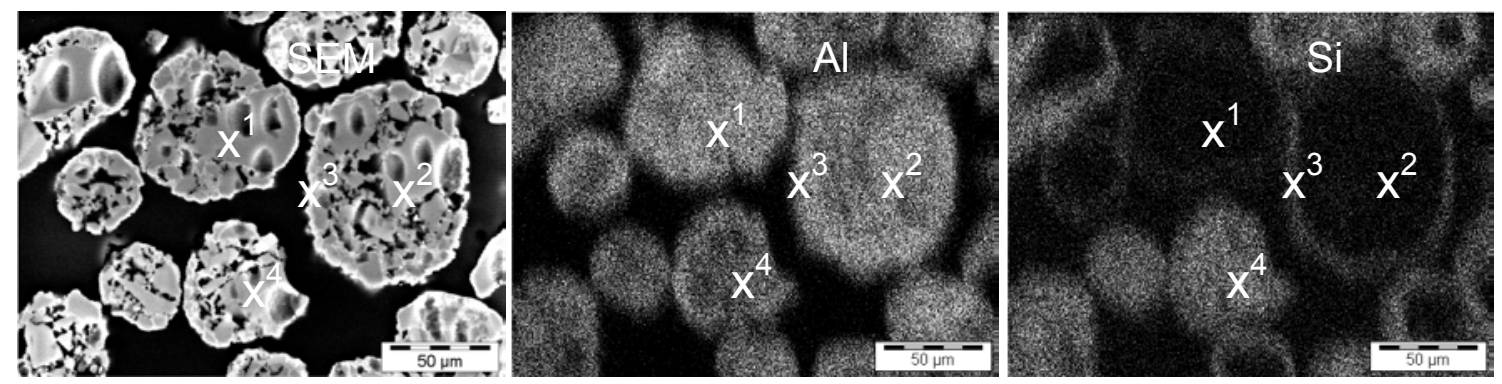

Figure 1. Metallocene/MAO/ silica catalyst system embedded in epoxy resin and sectioned. SEM micrograph and corresponding Siand Al-mappings. Crosses mark EDX spot measurements of the $\mathrm{Si} / \mathrm{Al}$ ratio.
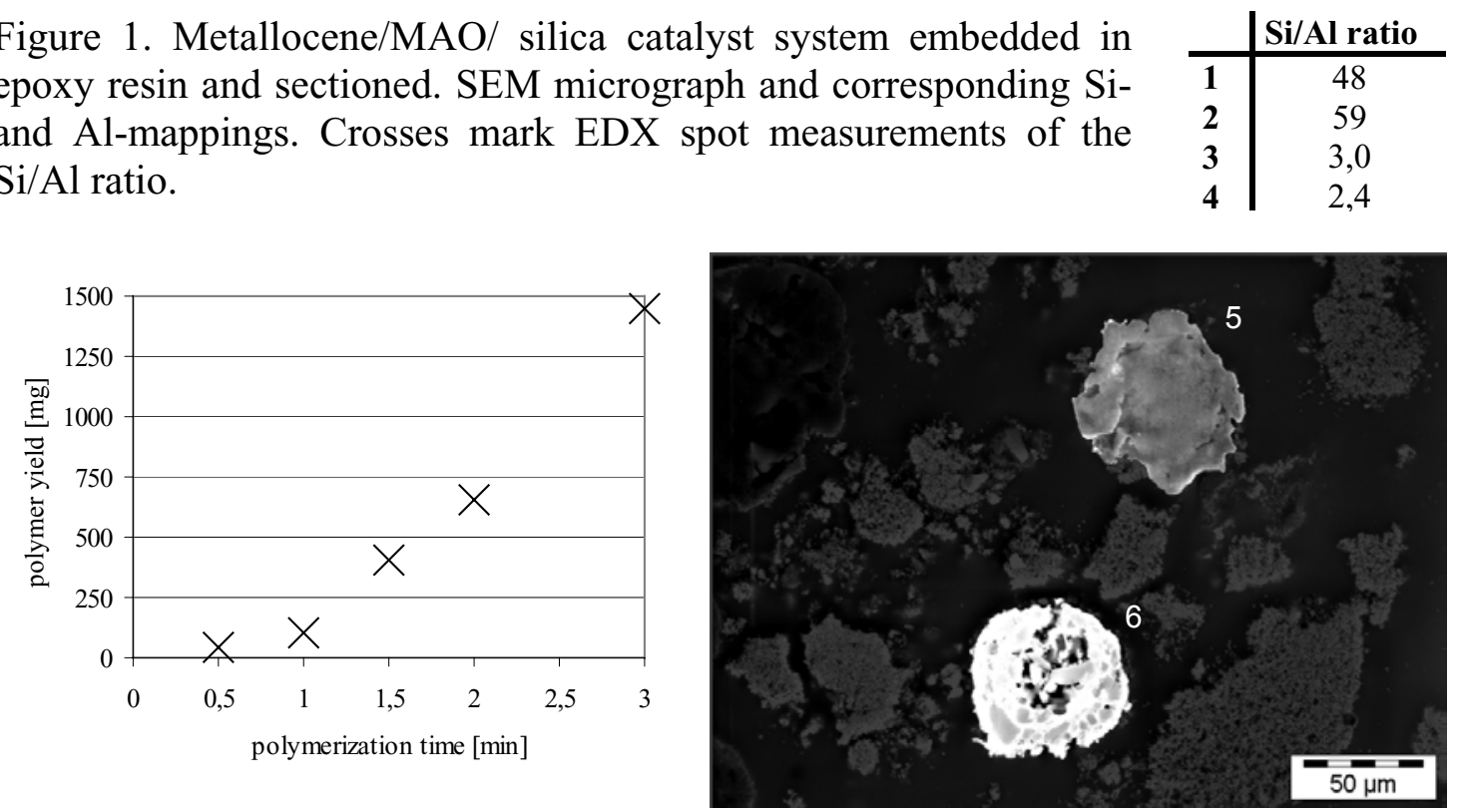

Figure 2. Plot of polymer yield versus polymerization time.

Conditions: $184,5 \mathrm{mg}$ catalyst in $350 \mathrm{~g}$ propene and $1 \mathrm{ml}$ Triisobutylaluminum in 1,81 reactor volume at $60^{\circ} \mathrm{C}$.

Figure 3. SEM/EDX measurements of the $\mathrm{Si} / \mathrm{Al}$ ratios correspond-

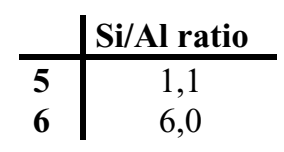

ing to certain particles after 1,5 minutes polymerization time. Highlighted areas mark measurements of the $\mathrm{Si} / \mathrm{Al}$ ratio.

\section{References}

1. Fink, G., Steinmetz, B., Zechlin, J., Przybyla, C. and Tesche, B. (2000) Chem. Rev. 100, 1377-1390.

2. a Korber, F., Hauschild, K., Fink, G., (2001) Macromol. Chem. Phys. 202(17), 3329-3333.

2. b Knoke, S., Korber, F., Fink, G., and Tesche, B., Macromol. Chem. Phys., accepted.

3. Knoke, S., Korber, F., Fink, G., and Tesche, B. (2001) Proc. Microsc. Microal. 7 , Bailey, G. W., Price, R. L., Voelk1, E. and Musselman, I. H., eds., Long Beach, California, USA, Springer, 2, 1088-1089. 